\title{
OS CURSOS DE CIÊNCIA DA INFORMAÇÃO NO BRASIL E EM PORTUGAL: PERSPECTIVAS DIACRÔNICAS
}

\author{
CURSOS DE CIENCIA DE LA INFORMACION EN BRASIL Y EN \\ PORTUGAL: PERSPECTIVAS DIACRÓNICAS
}

Terezinha Batista de Souza tbalista@uel.br

Doutoranda em Ciências Documentais pela Universidade do Porto, PT Docente do Departamento de Ciência da Informação da Universidade Estadual de Londrina

Fernanda Ribeiro fribeiro@letras.up.pt

Doutora pela Faculdade de Letras da Universidade do Porto (Portugal) Professora Auxiliar da Secção Autónoma de Jornalismo e Ciências da Comunicação da Universidade do Porto

\begin{abstract}
Resumo
Apresenta uma breve retrospectiva histórica da Ciência da Informação (Cl) no Brasil e em Portugal. No Brasil a $\mathrm{Cl}$ foi introduzida na década de $70 \mathrm{com}$ a implementação do Mestrado, no Instituto Brasileiro de Bibliografia e Documentação (IBBD) e em Portugal surgiu a partir dos cursos de pósgraduação em Ciências Documentais que evoluíram no sentido da adoção do termo Ciência da Informação, tendo em vista a implementação, em 2001, num esforço conjunto entre a Faculdade de Engenharia e a Faculdade de Letras da primeira Licenciatura em Cl. Neste sentido mostra as as diferenças e semelhanças, bem como o quadro atual da $\mathrm{Cl}$ nos dois países.
\end{abstract}

\section{Palavras-chave}

Ciência da Informação-Brasil; Ciência da Informação-Portugal.

\section{INTRODUÇÃO}

A Ciência da Informação, nascida formalmente em 1962, em uma reunião do Georgia Institute of Technology, é uma área científica, com identidade e unidade na perspectiva epistemológica e que abrange componentes aplicadas tais como a Biblioteconomia, a Arquivologia, a Gestão da Informação e os Sistemas Tecnológicos de Informação, todas elas centradas sobre um mesmo objeto de estudo e de trabalho - a Informação -, contextualizado em diferentes ambiências e serviços. 
O presente artigo apresenta a evolução da Ciência da Informação em dois contextos diferentes, isto é, no Brasil e em Portugal, ressaltando o fortalecimento da área com o surgimento de associações de classe, de periódicos científicos, da promoção de eventos e do surgimento de novos cursos em diferentes níveis de formação e pós.

Prosseguindo, mostra o cenário atual da Ciência da Informação nos dois países, através dos cursos e habilitações no Brasil em nível de graduação, mestrados e doutorados e em Portugal em nível de licenciatura, especialização, mestrado e doutoramento. As considerações finais encerram o trabalho, mostrando semelhanças e diferenças do desenvolvimento gradual e progressivo da $\mathrm{Cl}$ nos dois países.

\section{A CIÊNCIA DA INFORMAÇÃO NO BRASIL}

A década de 1960, no Brasil foi marcada por um aumento representativo no acervo do conhecimento da humanidade. Barbosa e outros (2000, p. 83) afirmam que a consequência dessa explosão informacional é que "pessoas e organizações enfrentam constantes desafios relacionados com o gerenciamento desse enorme volume de informação. A informação transformou-se em um fenômeno social contemporâneo analisado em vários campos científicos". Tudo isso levou a Biblioteconomia a alargar e aprofundar seu instrumental de observação e análise de seu objeto de estudo e pesquisa, isto é, a informação. Isso só foi possível por meio da:

[...] assimilação de recursos de outros campos do conhecimento que Ihe permitissem estudar e entender a produção e o registro de informações, seu armazenamento em diversos suportes, a organização para seu acesso, o processo de recuperação e as consequências sócioculturais de seu uso (BARBOSA et al., 2000, p. 84).

Vários autores brasileiros têm procurado ponderar sobre o desenvolvimento da área. Oddone (2005) afirma que a preocupação com o ensino na área de Ciência da Informação no Brasil ocorreu em 1956, no Rio de Janeiro, dois anos após a criação do Instituto Brasileiro de Bibliografia e Documentação (IBBD), quando foram criados os cursos de Pesquisas Bibliográficas. Estes eram direcionados a princípio, a bibliotecários brasileiros e muitas inovações já foram colocadas em prática, sendo a mais significante, a de permitir que "interessados que não fossem bibliotecários se matriculassem no curso", o que, em sua opinião, consistia "de uma visão mais internacional da biblioteconomia".

O Curso de Pesquisa Bibliográfica incluía em seu currículo conteúdos que não eram ministrados nas escolas de graduação, tais como a bibliografia especializada, normaliza- 
ção da documentação, mecanização dos serviços técnicos e outros. Posteriormente, essas matérias foram incluídas nos programas das escolas, com nomenclaturas diferentes (GOMES; ZAHER, 1972).

Segundo as palavras de Oddone (2005):

O IBBD instituiu um novo regime de informação no Brasil [...] não apenas [por causa] das novas práticas e posturas que o órgão adotou e disseminou entre bibliotecários e pesquisadores brasileiros, mas principalmente da força das novas construções teóricas que começaram a ser utilizadas no contexto do órgão.

Podemos inferir, portanto, com base nas afirmativas acima, que já não era apenas Biblioteconomia que se praticava e que se propagava nos cursos do IBBD. Havia sim novas posturas e novas mentalidades, novos conceitos e entre eles a Documentação.

Já para Pinheiro e Loureiro (1995, p. 48), a Ciência da Informação foi introduzida no Brasil no início da década de 70 com a implantação do Mestrado em Ciência da Informação, no IBBD. Este, a partir de 1976, refletindo a transformação ocorrida em outros países e a própria designação do seu curso de mestrado, abandona o termo documentação e passa a denominar-se Instituto Brasileiro de Informação em Ciência e Tecnologia - IBICT, órgão vinculado ao Conselho Nacional de Desenvolvimento Científico e Tecnológico CNPq. Nesta direção ainda podemos apontar outro passo dado pelo IBICT, que é a criação, em 1972, da revista Ciência da Informação, diretamente associada às atividades acadêmicas do seu curso de mestrado.

Segundo Odone (2006, p. 45) o principal objetivo do referido curso de Mestrado em Ciência da Informação era,

[...] permitir que os funcionários do órgão tivessem acesso aos conhecimentos e às competências profissionais que [...] a partir da segunda metade dos anos 1960, com a entrada em cena dos primeiros equipamentos eletrônicos, eram exigidos no desempenho de suas funções especializadas.

Além disso, o curso retratava a preocupação europeia e americana com a formação de profissionais para lidar com a grande produção de informação científica e tecnológica surgida do período pós-guerra e formava, sobretudo, profissionais oriundos de várias áreas do conhecimento, produzindo trabalhos voltados para outras áreas de aplicação da $\mathrm{Cl}$, que não a Biblioteconomia, o que ampliou os debates sobre os problemas e temas da $\mathrm{Cl}$ no Brasil. 
Cardoso (2002) coloca que a conjuntura nacional na década de 70 "exigia a criação de estruturas de apoio informacional e a capacitação de recursos humanos para a pesquisa e o desenvolvimento científico e tecnológico, necessários às estratégias de soberania econômica implantadas pelos governos militares". Diante deste cenário, encontravase, de um lado a Biblioteconomia e a Documentação, que até essa época desempenhavam as funções informativas, e de outro lado a Ciência da Informação que começava a incorporar o discurso teórico, a problemática de pesquisa e as metodologias de investigação.

O fortalecimento da Ciência da Informação no Brasil avança consideravelmente com a criação, em 1989, da Associação Nacional de Pesquisa e Pós-Graduação em Ciência da Informação (ANCIB). À semelhança de outras associações do mesmo gênero, a ANCIB tem o apoio do Conselho Nacional de Desenvolvimento Científico e Tecnológico (CNPq) e é hoje a principal sociedade científica da área e que vem, desde sua criação, promovendo Encontros Nacionais de Pesquisa em Biblioteconomia e Ciência da Informação. Sua finalidade é acompanhar e estimular as atividades de ensino de pós-graduação e de pesquisa em Ciência da Informação no Brasil. Desde sua criação, tem se projetado no país e fora dele, como uma instância de representação científica e política importante para o debate das questões pertinentes à área de informação.

Assim, podemos compreender de maneira bastante clara, que a Ciência da Informação se constituiu no Brasil - assim como no resto do mundo - rompendo com um passado de práticas que não se mostravam mais suficientes para atender às necessidades bibliográficas e documentais de uma sociedade marcada pelo surgimento das novas tecnologias de informação e telecomunicações e, principalmente, de uma comunidade científica em contínuo processo de crescimento.

Com o surgimento do Doutorado em Ciência da Informação que começou em 1992, após estudos decorrentes de uma linha de pesquisa específica para a área de Ciência da Informação, aberta dentro do Doutorado em Comunicação da Escola de Comunicação da Universidade Federal do Rio de Janeiro - Eco/UFRJ, em 1986, os contornos da Ciência da Informação foram alargando-se e novos profissionais foram surgindo e elaborando novas propostas epistemológicas e metodológicas para a área.

Isto posto, pode-se afirmar que a Ciência da Informação é uma área do conhecimento reconhecida nacional e internacionalmente por meio de cursos, instituições científicas, periódicos e outras formas de institucionalização. No Brasil, a designação foi introduzida há quase três décadas, indiscutivelmente, se consolidando cada vez mais. 
$\mathrm{Na}$ classificação das áreas do conhecimento do CNPq o termo Ciência da Informação constitui subárea das ciências sociais aplicadas compreendendo as seguintes modalidades conforme esquema abaixo:

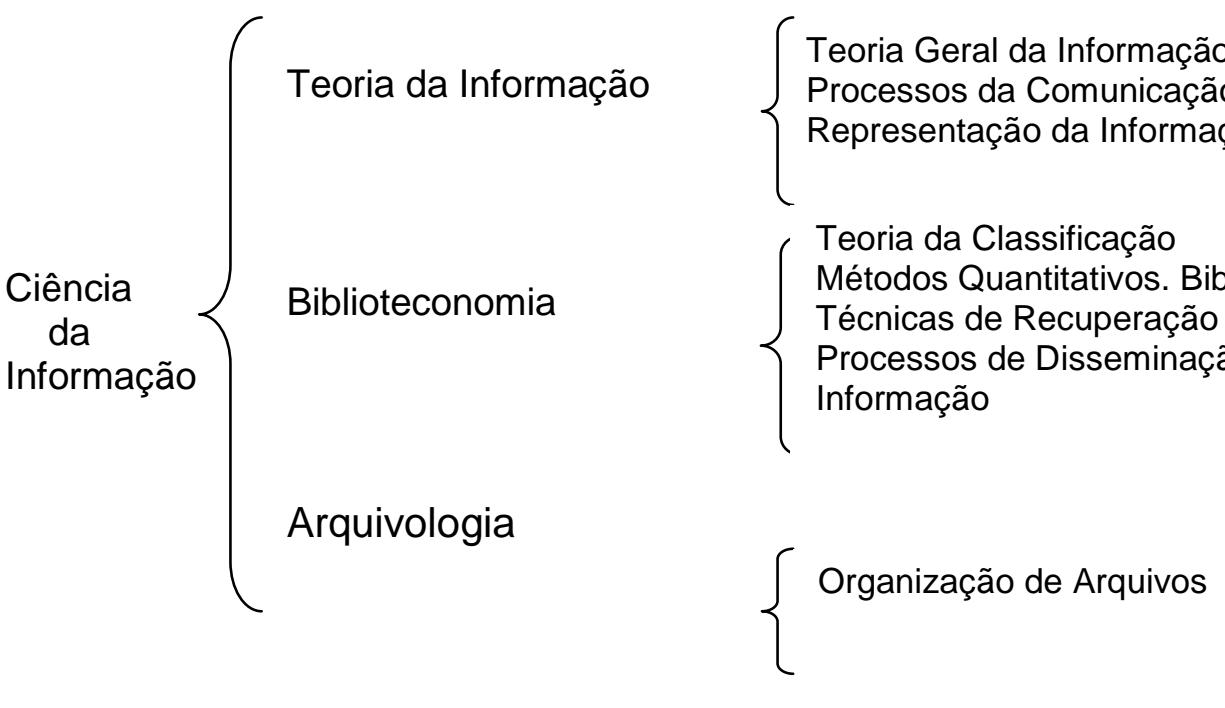

Figura 1 - Classificação da Área da Ciência da Informação - CNPq.

Fonte: Valentim (2005, p. 15).

Atualmente, o Brasil conta com 43 escolas de graduação oferecendo cursos de $\mathrm{Bi}$ blioteconomia, Arquivologia, Museologia, Ciência da Informação e Gestão da Informação. Algumas delas contam com mais de um curso. Desse total, 22 são em instituições federais, 7 em instituições estaduais e 14 em instituições privadas (cf. quadros 1, 2 e 3 ).

\begin{tabular}{|c|l|}
\hline \multicolumn{1}{|c|}{ Instituições Federais } \\
\hline $\mathbf{1}$ & Fundação Universidade Federal do Rio Grande (FURG) / Curso de Biblioteconomia \\
\hline $\mathbf{2}$ & $\begin{array}{l}\text { Universidade Federal da Bahia (UFBA)/Curso de Biblioteconomia e Documentação / Arquivologia / Mu- } \\
\text { seologia }\end{array}$ \\
\hline $\mathbf{3}$ & Universidade Federal da Paraíba (UFPB) / Curso de Biblioteconomia/Arquivologia (2006) \\
\hline $\mathbf{4}$ & Universidade Federal de Alagoas (UFAL) / Curso de Biblioteconomia \\
\hline $\mathbf{5}$ & Universidade Federal de Brasília (UnB) / Curso de Biblioteconomia/Curso de Arquivologia \\
\hline $\mathbf{6}$ & Universidade Federal de Goiás (UFG) / Curso de Biblioteconomia \\
\hline $\mathbf{7}$ & Universidade Federal de Minas Gerais (UFMG) / Curso de Biblioteconomia \\
\hline $\mathbf{8}$ & Universidade Federal de Pernambuco (UFPE) / Curso de Biblioteconomia \\
\hline $\mathbf{9}$ & Universidade Federal de Santa Catarina (UFSC) / Curso de Biblioteconomia \\
\hline $\mathbf{1 0}$ & Universidade Federal de Santa Maria (UFSM) / Curso de Arquivologia \\
\hline $\mathbf{1 1}$ & Universidade Federal de São Carlos (UFSCar) / Curso de Biblioteconomia \\
\hline $\mathbf{1 2}$ & Universidade Federal do Amazonas (UFAM) / Curso de Biblioteconomia \\
\hline $\mathbf{1 3}$ & Universidade Federal do Ceará (UFC) / Curso de Biblioteconomia \\
\hline $\mathbf{1 4}$ & Universidade Federal do Espírito Santo (UFES) / Curso de Biblioteconomia / Arquivologia \\
\hline $\mathbf{1 5}$ & $\begin{array}{l}\text { Universidade Federal do Estado do Rio de Janeiro (UNIRIO) / Curso de Biblioteconomia /Arquivologia/ } \\
\text { Museologia }\end{array}$ \\
\hline $\mathbf{1 6}$ & Universidade Federal do Maranhão (UFMA) / Curso de Biblioteconomia \\
\hline $\mathbf{1 7}$ & Universidade Federal do Mato Grosso (UFMT) / Curso de Biblioteconomia \\
\hline $\mathbf{1 8}$ & Universidade Federal do Pará (UFPA) / Curso de Biblioteconomia \\
\hline $\mathbf{1 9}$ & Universidade Federal do Paraná (UFPR) / Curso de Gestão da Informação \\
\hline $\mathbf{2 0}$ & Universidade Federal do Rio Grande do Norte / Curso de Biblioteconomia \\
\hline $\mathbf{2 1}$ & Universidade Federal do Rio Grande do Sul (UFRGS) / Curso de Biblioteconomia / Arquivologia \\
\hline $\mathbf{2 2}$ & Universidade Federal Fluminense (UFF) / Curso de Biblioteconomia \\
\hline
\end{tabular}

Quadro 1 - Instituições federais brasileiras que oferecem cursos na área de Ciência da Informação Fonte: ABECIN (2009) <http://www.abecin.org.br/portal/abecin/escolas.xls?sl=ens> 
Instituições Estaduais

1 Universidade de São Paulo (USP) / Curso de Biblioteconomia

2 Universidade de São Paulo (USP) - Campus Ribeirão Preto/Curso de Ciência da Informação e Documentação

3 Universidade Estadual Paulista (UNESP) / Curso de Biblioteconomia / Arquivologia

4 Universidade do Estado de Santa Catarina (UDESC) / Curso de Biblioteconomia

5 Universidade Regional do Noroeste do Est.Rio Gde. do Sul -UNIUUI / Licenciatura em Biblioteconomia

6 Universidade Estadual de Londrina (UEL) / Curso de Biblioteconomia / Curso de Arquivologia

7 Universidade Estadual da Paraíba / Curso de Arquivologia (2008)

Quadro 2 - Instituições estaduais brasileiras que oferecem cursos na área de Ciência da Informação Fonte: ABECIN (2009) <http://www.abecin.org.br/portal/abecin/escolas.xls?sl=ens>

\begin{tabular}{|l|l|l|l|}
\hline \multicolumn{2}{|c|}{ Instituições Confessionais/Comunitárias } & \multicolumn{1}{c|}{ Instituições Privadas } \\
\hline $\mathbf{1}$ & $\begin{array}{l}\text { Faculdades Integradas Coração de Jesus } \\
\text { (FAINC)Faculdade de Biblioteconomia -Santo André- SP } \\
\text { Curso de Biblioteconomia }\end{array}$ & $\mathbf{1}$ & $\begin{array}{l}\text { Faculdades Tereza Martin (FATEMA) /Curso } \\
\text { Administração da Informação São Paulo }\end{array}$ \\
\hline $\mathbf{2}$ & $\begin{array}{l}\text { Faculdades Integradas Faculdades Tereza Martin } \\
\text { (FATEMA) Santo André / Curso Administração da Informa- } \\
\text { ção }\end{array}$ & $\begin{array}{l}\mathbf{2} \\
\text { Faculdades Integradas Teresa D'Ávila (FATEA) Lorena } \\
\text { /Curso de Biblioteconomia } \\
\text { ções (UNINCOR) /Curso de Biblioteconomia }\end{array}$ & $\mathbf{3}$ \\
\hline $\mathbf{4}$ & $\begin{array}{l}\text { Fundação Comunitária Formiguense (UFOM) /Curso de } \\
\text { Biblioteconomia } \\
\text { tação em Gestão da Informação Florianópolis, } \\
\text { SC }\end{array}$ & $\begin{array}{l}\text { Instituto de Ensino Superior da Funlec (IESF) / } \\
\text { Curso de Biblioteconomia, Campo Grande, } \\
\text { Mato Grosso do Sul }\end{array}$ \\
\hline $\mathbf{5}$ & $\begin{array}{l}\text { Pontifícia Universidade Católica de Campinas (PUCCAMP) } \\
\text { /Curso de Ciência da Informação }\end{array}$ & $\begin{array}{l}\text { Universidade Presidente Antônio Carlos- } \\
\text { (UNIPAC) /Curso de Biblioteconomia-Ubá, MG }\end{array}$ \\
\hline $\mathbf{6}$ & $\begin{array}{l}\text { Pontifícia Universidade Católica de Minas Gerais (PUC- } \\
\text { MINAS) /Curso de Ciência da Informação }\end{array}$ & $\begin{array}{l}\text { Fundação Escola de Sociologia e Política de } \\
\text { São Paulo(FESP) /Curso de Biblioteconomia }\end{array}$ \\
\hline $\mathbf{7}$ & $\begin{array}{l}\text { Universidade Santa Úrsula (USU) / Curso de Biblioteco- } \\
\text { nomia, Rio de Janeiro }\end{array}$ & $\mathbf{7}$ & $\begin{array}{l}\text { Centro Universitário de Formiga (UNIFOR) - } \\
\text { MG Curso de Biblioteconomia }\end{array}$ \\
\hline
\end{tabular}
Quadro 3 - Instituições confessionais, comunitárias e privadas brasileiras que oferecem cursos na área de $\mathrm{Cl}$ Fonte: ABECIN (2009)<http://www.abecin.org.br/portal/abecin/escolas.xls?sl=ens>

A multiplicação de cursos da área de Ciência da Informação no Brasil, nos últimos oito anos, tem mostrado uma diversificação de conteúdos. Além da Biblioteconomia (ainda majoritária entre os cursos brasileiros) e da Arquivologia, o surgimento de formações em Ciência da Informação, Gestão da Informação e Administração da Informação, mostra o dinamismo da área como se pode constatar nos quadros 1, 2 e 3 acima. O Quadro 4, a seguir, relaciona os cursos e habilitações na área de Ciência da Informação no Brasil, em nível de graduação:

\begin{tabular}{|l|c|}
\hline \multicolumn{1}{|c|}{ Cursos/Habilitações } & N. \\
\hline Biblioteconomia & 34 \\
\hline Arquivologia & 10 \\
\hline Ciência da Informação & 3 \\
\hline Museologia & 2 \\
\hline Gestão da Informação & 2 \\
\hline Administração da Informação & 1 \\
\hline Total & $\mathbf{5 2}$ \\
\hline
\end{tabular}

Quadro 4 - Cursos e habilitações em Ciência da Informação no Brasil.

Fonte: ABECIN ( 2008) <http://www.abecin.org.br/portal/abecin/escolas.xls?sl=ens>. 
Embora o Brasil também possua muitos cursos de pós graduação em nível de especialização, mostraremos a seguir a situação atual relativamente aos cursos de mestrado e doutorado, tendo em vista que ocorre muitas mudanças nas ofertas das especializações.

\begin{tabular}{|l|l|l|}
\hline \multicolumn{1}{|c|}{ Instituições } & \multicolumn{1}{c|}{ Cursos } \\
\hline $\mathbf{0 1}$ & Universidade Federal da Bahia / Ciência da Informação & Mestrado \\
\hline $\mathbf{0 2}$ & Universidade Federal da Paraíba / Ciência da Informação & Mestrado \\
\hline $\mathbf{0 3}$ & Universidade Federal de Pernambuco / Ciência da Informação & Mestrado \\
\hline $\mathbf{0 4}$ & Universidade Federal do Rio de Janeiro / Ciência da Informação & Mestrado e Doutorado \\
\hline $\mathbf{0 5}$ & Universidade Federal Fluminense / Ciência da Informação & Mestrado \\
\hline $\mathbf{0 6}$ & Universidade Federal de Santa Catarina / Ciência da Informação & Mestrado \\
\hline $\mathbf{0 7}$ & Universidade de São Paulo / Ciência da Informação & Mestrado e Doutorado \\
\hline $\mathbf{0 8}$ & Universidade Estadual Paulista / Ciência da Informação & Mestrado e Doutorado \\
\hline $\mathbf{0 9}$ & Universidade de Brasília / Ciências da Informação & Mestrado e Doutorado \\
\hline $\mathbf{1 0}$ & Universidade Federal de Minas Gerais / Ciências da Informação & Mestrado e Doutorado \\
\hline $\mathbf{1 1}$ & Universidade Federal Fluminense / Ciências da Informação & Mestrado e Doutorado \\
\hline $\mathbf{1 2}$ & Universidade Estadual de Londrina / Gestão da Informação & Mestrado Profissional \\
\hline
\end{tabular}

Quadro 5 - Mestrados e Doutorados em Ciência da Informação no Brasil.

Fonte: Coordenação de Aperfeiçoamento de Pessoal de Nível Superior - Capes (2009).

\section{A CIÊNCIA DA INFORMAÇÃO EM PORTUGAL}

$\mathrm{Na}$ Europa, a formação de arquivistas e bibliotecários teve suas raízes no trabalho diário de pessoas que trabalhavam nas instituições - destacadamente bibliotecas e arquivos nacionais - que tinham como missão salvaguardar toda a documentação das nações. Sendo assim, essas instituições se tornaram locais adequados à época, para "formar" tais profissionais. Tratava-se na verdade de "uma via destinada ao exercício de uma profissão, mais do que a aquisição de saberes tendentes a estimular o estudo e o conhecimento numa dada área disciplinar" (RIBEIRO, 2002, p. 420).

Portugal foi um dos países pioneiro no mundo a criar cursos de formação superior na área da Informação/Documentação, formação essa que seguia o modelo dos cursos ministrados pelas associações e escolas profissionais, isto é, a formação "em serviço".

Posteriormente, a Inspecção Geral das Bibliothecas e Archivos Públicos, criada pelo Decreto de 29 de Dezembro de 1887, instituiu o curso de instrução superior, denominado de bibliothecario-archivista. A esse respeito Fernanda Ribeiro (2006, p.6) assevera:

[...] verificamos que Portugal é dos primeiros países a estabelecer uma ligação entre a formação profissional e a formação superior de tipo universitário e a integrar num mesmo curso a instrução de profissionais de uma mesma área técnico-científica, ou seja, os bibliotecários e os arquivistas - insere as disciplinas específicas para o exercício da profissão no contexto das instituições onde futuramente os diplomados irão exercer a sua actividade. 
Ao longo dos anos, o curso de bibliothecario-archivista passou por profundas modificações, entretanto, sua matriz historicista e patrimonialista sempre permaneceu como uma característica marcante. Essas alterações não satisfaziam as necessidades e exigências dos profissionais daquela época.

A promulgação da República, ocorrida em 5 de Outubro de 1910, que trouxe como consequência o interesse pelos assuntos culturais e pela defesa do ensino público, o que por sua vez exigia mais acesso à informação e à leitura, levou a uma reforma legislativa na área das bibliotecas e arquivos em Portugal.

Esse período foi marcado por três acontecimentos importantes: a criação das Universidades de Lisboa e do Porto e o Curso Superior de Letras, que à época funcionava nas instalações da então Academia das Ciências de Lisboa, é integrado na Universidade de Lisboa. Foi dessa maneira que o Curso de Bibliotecário-Arquivista passou a ser em nível universitário.

Por conseguinte, esse foi o início da formação, em nível universitário, a qual tem sido, desde então, um requisito indispensável para o exercício profissional de arquivista, bibliotecário e documentalista na administração pública de Portugal.

No ano de 1918, ocorre uma nova "remodelação dos serviços biblioteconômicos e arquivísticos", e no contexto desta reforma, também o Curso Superior de BibliotecárioArquivista é reformulado. Impunha-se, pois, "não introduzir nesse curso senão as disciplinas consideradas absolutamente indispensáveis". Com efeito, o novo regulamento discrimina as disciplinas distribuídas pelos três anos do Curso, notando-se uma valorização da componente técnica (RIBEIRO, 2006).

No ano seguinte, (Maio de 1919), o Curso de Bibliotecário-Arquivista sofreu uma alteração de nome, passando a ser designado "Curso de Biblioteconomia e Arquivística". No entanto, as remodelações mais significativas em sua natureza e estrutura só ocorreram em 1931.

Fruto de um novo contexto político centralizador e de uma reforma estrutural das bibliotecas e arquivos estatais, a legislação de 1931 converteu o Curso Superior de Bibliotecário Arquivista num curso "exclusivamente profissional", passou a admitir bachareis ou licenciados pelas faculdades de Letras, e passou a ter a duração de dois anos, cujo objetivo, segundo Pinto $(2008$, p.108) "era fornecer formação técnica para prover os cargos superiores de bibliotecas e arquivos, configurando uma 'pós-graduação' dado que implicava a posse 
prévia do grau de bacharel ou licenciado pelas faculdades de Letras (ou posse de um determinado elenco de disciplinas)".

O Regulamento do Curso Superior de Bibliotecário Arquivista determinava, detalhadamente, o funcionamento do Curso junto da Inspecção Geral das Bibliotecas e Arquivos e já não mais sob a responsabilidade da Faculdade de Letras da Universidade de Lisboa. Passa a ser a partir daí, um curso técnico de mais curta duração, e sem as disciplinas de caráter geral que antes existiam.

A mudança ocorrida em 1931 foi, talvez, a mais significativa desde a criação do Curso. Fortaleceu a sua vertente técnica, centralizou recursos e introduziu na formação a perspectiva dirigista que começava a caracterizar todo o sistema político e o regime que se consolidava.

Cabia à Inspecção Geral das Bibliotecas e Arquivos a função de determinar as orientações, e à Junta Consultiva das Bibliotecas e Arquivos a execução das diretrizes impostas pela referida Inspecção, elaborando, portanto, os programas das disciplinas do Curso de Bibliotecário-Arquivista, pela primeira vez, tais programas foram aprovados legalmente, e possuíam "carácter historicista, patrimonialista e tecnicista, que caracterizava o modelo de formação [...] com raízes na Revolução Francesa e já plenamente consolidado" (SILVA; RIBEIRO, 2002, p.145).

Esta experiência de "formação em serviço" sem a parceria de uma instituição de ensino permaneceu por pouco tempo e o regresso à Universidade acontece em 1935, com a transferência do Curso de Bibliotecário-Arquivista para Faculdade de Letras da Universidade de Coimbra - instituição que reunia à época condições favoráveis para sua realização - o Curso Superior de Bibliotecário-Arquivista. Este curso seguia o modelo que desde o começo serviu de base para a formação neste país, tinha duração de dois anos letivos e um estágio de seis meses.

A Faculdade de Letras da Universidade de Coimbra conservou, em seu poder, o Curso de Bibliotecário-Arquivista, durante quase meio século, e consequentemente, a formação de arquivistas e bibliotecários, manteve-se sem nenhuma alteração até 1982, quando foi extinto.

As transformações sociais, econômicas e, principalmente, tecnológicas impulsionadas pela Sociedade da Informação, bem como aos desafios que se apresentavam aos profissionais das bibliotecas e dos arquivos, notadamente a partir da década de 1970, tornaram o Curso de Bibliotecário-Arquivista arcaico. 
Sucederam-se, ininterruptamente, tentativas de reestruturação do curso, para a sua adequação a essa nova realidade que se apresentava, porém, somente quase cinco décadas após a criação do curso original é que se conseguiu esse objetivo, através da criação, por proposta da Faculdade de Letras da Universidade de Coimbra, do Curso de Especialização em Ciências Documentais - CECD o qual extinguiu, simultaneamente, o Curso de Bibliotecário-Arquivista.

Percebe-se nessa altura o aparecimento da palavra "ciências" que segundo Fernanda Ribeiro (2005, p.19)

[...] querendo significar a junção de várias disciplinas, presumivelmente científicas, num mesmo modelo formativo, mais actualizado e mais em consonância com os desafios técnicos e tecnológicos que a Sociedade da Informação emergente ia colocando inevitavelmente.

Nota-se, portanto, até pela própria designação do curso - Especialização em Ciências Documentais (CECD) - uma pequena evolução, embora ainda permaneça o caráter historicista, custodial e tecnicista.

Essa nova proposta permitia que o CECD fosse ministrado nas Universidades que reunissem os recursos humanos e materiais necessários. As condições de acesso, o plano curricular, o regime de estudos e as propinas, bem como o regime de cessação do curso foram regulados por Portarias.

Portanto, o primeiro Curso de Especialização em Ciências Documentais foi criado na Faculdade de Letras da Universidade de Coimbra (1982).

Pinto (2008, p.113), afirma que o curso

[...] 'visa a formação de profissionais qualificados no domínio das ciências documentais, com vista a conceber, planificar, gerir, explorar e manter serviços de documentação e informação, de biblioteca e arquivo', sendo admitidos como candidatos ao curso os detentores de licenciatura em qualquer área do saber, com o domínio de [pelo menos] uma língua.

Complementando a autora acima citada, com relação à mudança estrutural do CECD, afirma que "em termos de modelo formativo [...] o curso se passa a desdobrar em duas opções - 'Arquivo' e 'Documentação e Biblioteca' - quebrando o carácter unitário que, desde o seu início, caracterizou a formação em Portugal”.

A partir daí, o CECD, apresentado com o estatuto de "pós-graduação" passou a ser a "matriz definidora da formação, sendo reconhecido como imprescindível para o provimento dos lugares de técnicos superiores de Arquivo ou de Bibliotecas e Documentação, 
nos quadros dos organismos da administração pública [de Portugal]" (SILVA; RIBEIRO, 2002, p.148).

Entretanto, pouco tempo depois da sua criação, o CECD, foi alvo de críticas principalmente por parte dos profissionais que já o consideravam como um curso que não atendia às necessidades dos profissionais e do mercado de trabalho à época.

A expectativa e demanda por um curso que atendesse aos anseios de pessoas que queriam seguir a carreira profissional na área da BAD aliados à carência e a necessidade de uma formação profissional que atendesse essa nova realidade promoveram debates em conferências promovidas pelas próprias universidades que mantinham o curso, e um dos eventos mais significativos foi a comemoração do 10‥ aniversário do CECD da Faculdade de Letras da Universidade do Porto - FLUP, em julho de 1995, ocasião em que esta Faculdade organizou uma mesa-redonda subordinada ao título Formação profissional na área $B A D$ "evento em que os docentes promoveram algumas actividades, que, no essencial tiveram por objetivo avaliar e reflectir sobre o próprio modelo formativo subjacente ao CECD" (RIBEIRO; LEITE; CERVEIRA, 2004, p. 27).

Nesta ocasião, segundo Silva e Ribeiro (2002, p.18), as discussões se debruçaram sobre a:

[...] problemática da formação, questionando-se o modelo em vigor, a desactualização dos conteúdos e as lacunas que revelavam, enfin, os pressupostos teóricos em que deveria assentar a discussão conducente a uma reestruturação dos cursos ou ao surgimento de novos modelos formativos.

Neste evento, diversas intervenções foram feitas com relação à formação vigente, quando profissionais, estudantes e professores sinalizaram com firmeza a necessidade de repensar o modelo existente.

Nas palavras de Ribeiro; Leite e Cerveira, (2004, p.28) "Este encontro congregou um conjunto de personalidades que, pela sua experiência profissional ou posicionamento institucional, se encontravam em posição de reflectir sobre o (s) modelo(s) formativo(s) para os profissionais da chamada área BAD".

As preocupações levantadas neste evento, na FLUP, permaneceram e foram discutidas em outros eventos universitários e profissionais. Cada vez mais concluía-se que havia necessidade de uma inadiável mudança, "na formação tecnicista e de matriz patrimonial e positivista, inspirada por um paradigma anacrónico e em crise, incapaz de superar 
os novos desafios do pó-industrialismo da segunda metade de Novecentos" (SILVA; RIBEIRO, 2002, p.18).

No ano seguinte, em março de 1996, no âmbito das comemorações dos 60 anos do Curso de Bibliotecário-Arquivista, a Faculdade de Letras da Universidade de Coimbra organizou um painel cujo tema era "Formação profissional BAD em Portugal". Nessa ocasião o CECD do Porto, apresentou uma intervenção.

Na opinião de Ribeiro; Leite e Cerveira (2004, p. 28),

[...] estas duas iniciativas foram, de algum modo, o embrião de um futuro trabalho de reflexão conjunta de docentes dos CECD do Porto e de Coimbra, que esteve na base da produção de um estudo editado em 2002 e que influenciou grandemente o novo modelo de formação consubstanciado pela Licenciatura em Ciência da Informação [atualmente em vigor].

Em dezembro de 1997, a Associação Portuguesa de Bibliotecários Arquivistas e Documentalistas promoveu, na cidade de Braga, uma Conferência Nacional sobre a Formação e Carreiras $B A D$ à qual compareceram representantes dos diferentes cursos existentes em Portugal, com a finalidade de debaterem aspectos relativos à formação.

No ano seguinte, o tema foi novamente discutido pela Universidade Autónoma de Lisboa, quando das comemorações do 10‥ aniversário do CECD daquela instituição, num evento cujo tema versou sobre Formação BAD no limiar do sec. XXI ocasião também em que foi apresentada a "remodelação a que o Curso fôra sujeito, no sentido de uma actualização face às novas exigências profissionais" (SILVA; RIBEIRO, 2002, p.149).

Foi a partir da realização desta Mesa-redonda que os professores, estudantes e demais profissionais envolvidos pelos CECD e preocupados com a formação em nível superior em Portugal, se uniram coletivamente no sentido de repensar a reestruturação curricular, bem como a fundamentação epistemológica da área científica de um novo modelo formativo no país.

O primeiro fruto desse trabalho foi um estudo, que posteriormente veio a ser publicado em forma de livro, denominado Das "Ciências" Documentais à Ciência da Informação: ensaio epistemológico para um novo modelo curricular". ${ }^{1}$ Concomitantemente, e cumprindo o objetivo inicialmente proposto, "e por iniciativa dos docentes do CECD, foi possível criar [na Universidade do Porto] a primeira licenciatura em Ciência da Informação, estruturada em consonância com os pressupostos teóricos expostos neste ensaio" (SILVA; RIBEIRO, 2002, p.19).

\footnotetext{
${ }^{1}$ SILVA, Armando B. Malheiro; RIBEIRO, Fernanda. Das "ciências" documentais à ciência da informação: ensaio epistemológico para um novo modelo curricular. Porto: Afrontamento, 2002.
} 
Foi assim que a Faculdade de Letras e a Faculdade de Engenharia da Universidade do Porto elaboraram, com as bases mínimas para assegurar uma dinâmica pedagógica e científica no campo da Ciência da Informação, o projeto da Licenciatura em Ciência da Informação $\mathrm{LCl}$, o qual foi submetido aos órgãos competentes de ambas as universidades, obtendo, por unanimidade, a aprovação. Posteriormente obteve as aprovações pelo Senado da Universidade do Porto em 21 de Março de 2001 e foi homologado em 6 de Junho deste mesmo ano de 2001, cuja publicação saiu no Diário da República, nesta mesma data.

A primeira turma da nova licenciatura - a primeira na Universidade portuguesa - entrou em funcionamento no ano letivo de 2001-2002, com um número de trinta alunos o que, representando, segundo as palavras de Ribeiro; Leite e Cerveira (2004).

[...] uma mudança paradigmática na formação ministrada através da Universidade do Porto. Fechou-se um ciclo, isto é, encerrou-se o modelo tradicional, destinado, sobretudo, a formar técnicos de BAD, que ocupavam lugares dos quadros da administração pública, à frente de serviços culturais de acentuado cariz patrimonialista. Abriu-se um novo campo para a formação de gestores de informação, preparados para enfrentar os desafios colocados pela tecnologia e para responder com soluções eficazes aos problemas informacionais que ocorrem nos mais variados contextos.

A exemplo da Universidade do Porto, outras licenciaturas surgiram em Portugal, e atualmente existem doze instituições que oferecem a licenciatura em $\mathrm{Cl}$.

Quanto ao curso de Especialização em Ciências Documentais, continua sendo ofertado em Portugal, por várias instituições ${ }^{2}$, e atualmente possui uma estrutura onde há uma separação entre arquivistas e bibliotecários/documentalistas, por meio da criação de duas vertentes bastante distintas, no segundo ano do curso: Arquivo e Biblioteca/Documentação.

A Ciência da Informação em Portugal, assim como em outros países, tem recebido contributos de áreas como as chamadas ciências documentais, mais diretamente relacionadas com a Biblioteconomia e a Arquivologia, a comunicação social, os sistemas de informação de gestão ou as tecnologias da informação. Entretanto, em Portugal, a Ciência da Informação é uma ciência ainda jovem e em formação, que carece de estruturas que promovam o seu desenvolvimento, a sua afirmação e a sua disseminação.

Armando Malheiro da Silva e Fernanda Ribeiro são os mais importantes teóricos portugueses da Ciência da Informação. Sua jã citada obra Das "Ciências" documentais à Ciência da Informação: ensaio epistemológico para um novo modelo curricular ${ }^{3}$, publicada

\footnotetext{
${ }^{2}$ Para maiores informações consultar o site da Associação Portuguesa de Bibliotecários, Arquivistas e Documentalistas (BAD): http://www.apbad.pt/Formacao/formacao_cdisp.htm\#Pós-graduação_

${ }^{3}$ SILVA ; RIBEIRO, op. cit.
}

Inf. Inf., Londrina, v. 14, n. 1, p. 82 - 102, jul./jun. 2009 
em outubro de 2002, com base na reflexão produzida no país por um grupo de docentes e profissionais das universidades do Porto, Coimbra e Minho em torno dos modelos de formação tradicional de bibliotecários, documentalistas e arquivistas, é o documento mais significativo encontrado na literatura portuguesa sobre a evolução da $\mathrm{Cl}$ em Portugal.

Foi no âmbito da crise do modelo formativo (transição da década de 90 para o novo milênio) predominante nos cursos de pós-graduação de bibliotecários, arquivistas e documentalistas existentes em Portugal, Silva e Malheiros, envolvidos no esforço de investigar alternativas para este modelo (que consideram esgotado) procuraram definir o posicionamento da sua área disciplinar para, a partir daí, poderem formular novas soluções, ao nível da formação, mais próximas das atuais necessidades profissionais, de investigação e de docência. Dentro desse percurso de pesquisa, estabeleceram como objetivo o aprofundamento dos fundamentos epistemológicos da Ciência da Informação e o esclarecimento de um conjunto de questões que the estão associadas (PENTEADO, 2005, p. 96).

Dentre várias, duas foram as principais indagações para que Silva e Ribeiro (2002, p.18) abrissem um debate que levassem a uma reestruturação dos cursos ou ao surgimento de novos modelos formativos na área de $\mathrm{Cl}$ em Portugal:

1‥ Quais as implicações formativas de uma perspectiva epistemológica que parta da informação como fenómeno/processo gerado, transformado, difundido e transferido por diferentes suportes e modelos tecnológicos, com destaque hoje, para as poderosas e determinantes tecnologias da Informação e da Comunicação (TIC);

$2^{a}$. Que profissional podemos realmente formar? Continuaremos a formar o clássico "guardador de papeis" e o "animador de Leitores e Leituras" ou um especialista (cientista) em informação ajustado aos múltiplos desafios da Sociedade da Informação?

A Arquivologia e a Biblioteconomia estiveram, durante o século XX, limitadas a dois campos técnico-profissionais autônomos, sendo em vários países uma formação em separado (Brasil, por exemplo), com inclusão em diversas áreas científicas. Embora algumas escolas tenham tentado, nos últimos anos, um currículo mais integrado, com a intenção de formar profissionais com um perfil mais moderno, a verdade é que "tal modelo não conseguiu superar o paradigma tecnicista e documental que enfatiza a função serviço e todos os procedimentos inerentes ao acesso a informação, em detrimento de um conhecimento científico da própria informação" (SILVA; RIBEIRO, 2002, p.150).

Por isso, os autores acima citados propõem um novo modelo cujo objetivo é anular essas separações e desenvolver-se em torno de um conjunto de disciplinas nucleares da $\mathrm{Cl}$. 
Uma determinada disciplina pode ser chamada de nuclear "[...] quando tem a propriedade de, em determinada série ou em determinado curso, desempenhar a função de agente de articulação interdisciplinar, dada sua importância relativa no conjunto das disciplinas da série ou do curso" (NAGLE; CASALECCHI, 2007).

Para Silva e Ribeiro, a existência de um campo próprio, assim configurado, deve ainda ser entendida no quadro de um novo paradigma científico e pós-custodial em oposição ao paradigma técnico e custodial, associado a uma visão historicista e patrimonialista. Do ponto de vista teórico, esta perspectiva da $\mathrm{Cl}$ encontra-se ainda vinculada à teoria sistêmica e, metodologicamente, ao método quadripolar, elaborado por Paul de Bruyne e outros, em 1974, com base em quatro pólos - epistemológico, teórico, técnico e morfológico que intervêm na elaboração do conhecimento científico da área (PENTEADO, 2005, p. 98).

O método quadripolar (Figura 2) já adaptado pelos autores no que concerne ao domínio arquivístico, é agora alargado a toda a $\mathrm{Cl}$.

[...] constitui-se como dispositivo de investigação complexo, por exigência de um conhecimento que está longe de ser "unidimensional", de ser desprovido de variáveis ou de ser circunscrito apenas à tecnicidade dos procedimentos standard (ordenar, descrever a forma e o conteúdo informativo dos documentos, instalá-los e cotá-los), e que, bem antes pelo contrário, abarca toda a fenomenalidade informacional cognoscível. As técnicas aplicadas habitualmente "à custódia, à salvaguarda e à comunicação dos Fundos e das Colecções bibliográficas" já não resistem sequer a um leve confronto com o dispositivo metodológico proposto (SILVA; RIBEIRO, 2002, p. 86).

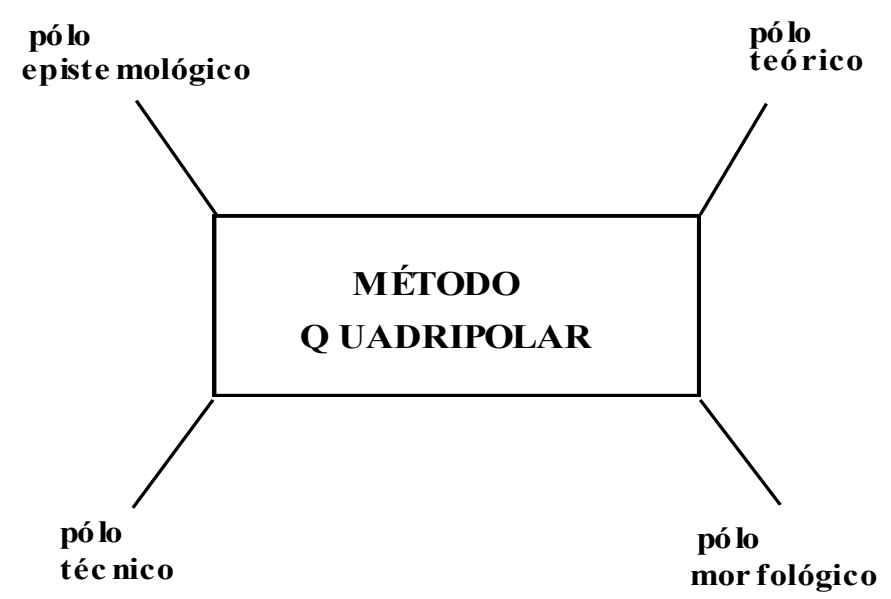

Figura 2 - Método Quadripolar.

Fonte: Silva e Ribeiro (2002, p. 86). 
De acordo com o referido método, a pesquisa científica não deve limitar-se a uma visão meramente tecnológica ou instrumental, mas ser projetada de forma a superar-se o debate "tradicional" entre "quantitativo" e "qualitativo" e de forma ainda a promover-se o tão almejado intercâmbio interdisciplinar. "Uma investigação que se cumpre em cada projeto e se reinicia, prolonga, corrige e supera no seguinte, implicando sempre a interacção e a abertura desses quatro pólos" (SILVA; RIBEIRO, 2002, p. 87).

O modelo formativo inter e transdisciplinar que propõem Silva e Ribeiro (2002), com base em reflexões epistemológicas, apresenta uma área científica nuclear em torno da $\mathrm{Cl}$, - onde se evidencia a transdisciplinariedade - e uma outra complementar, com a Informática e a Computação, diversas disciplinas das Ciências Sociais e Humanas e das Ciências Naturais etc. (cf.figura 3). Entre a área nuclear incluem-se as "cadeiras" que "atentam nas especificidades dos diversos tipos de sistemas de informação (arquivos, bibliotecas ou sistemas tecnológicos de armazenamento e recuperação da informação), direccionadas, por isso, para as componentes da própria Cl" (SILVA; RIBEIRO, 2002, p.151). A proposta refere-se, sobretudo, a uma formação ao nível de licenciatura, embora os autores pretendam futuramente aprofundá-la em cursos de pós-graduação, em nível de mestrado e doutoramento.

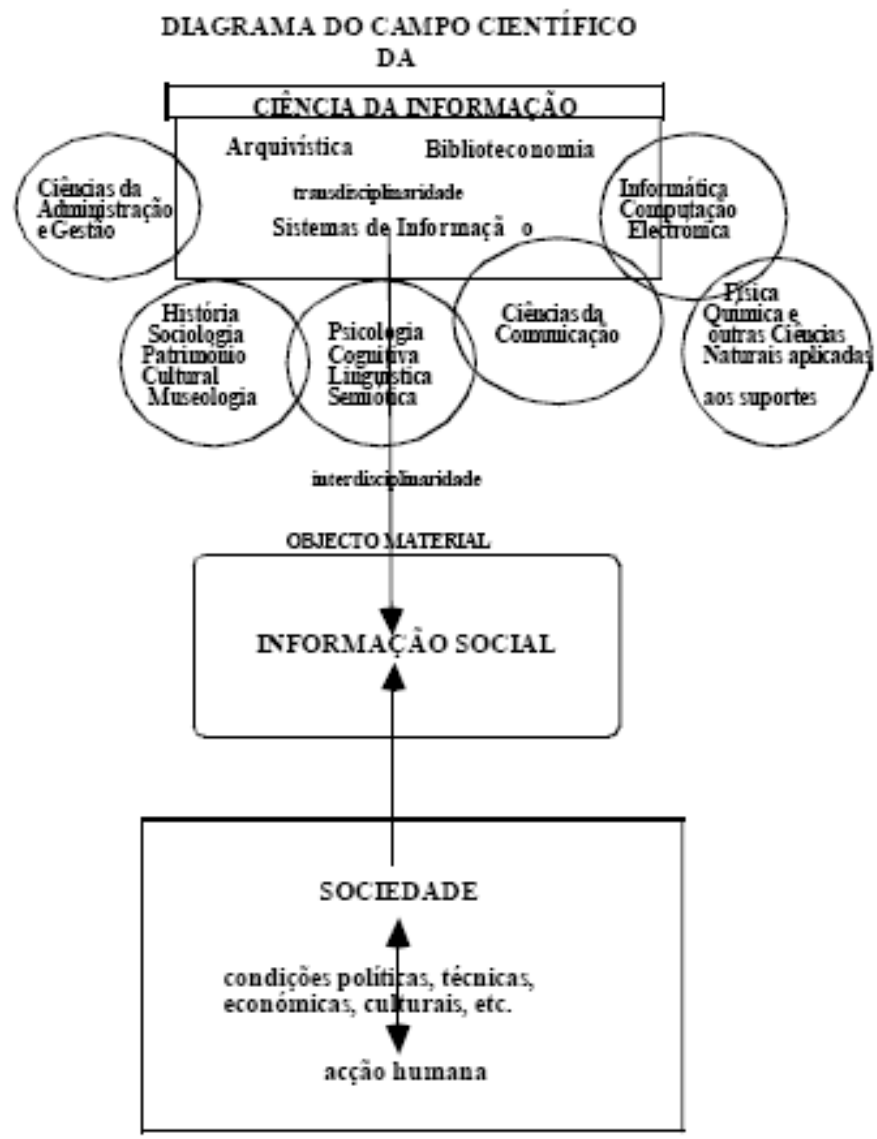

Figura 3 - Diagrama do campo científico da Cl proposto por Silva e Ribeiro. 
Fonte: Silva e Ribeiro (2002, p. 80).

Conforme mencionado anteriormente, em Março de 2001, concretiza-se esse novo modelo formativo, com a entrada em funcionamento da primeira $\mathrm{LCl}$, ministrado em conjunto pela Faculdade de Letras e pela Faculdade de Engenharia da Universidade do Porto, tendo como pretensão:

[...] garantir uma formação adequada à nova realidade da Sociedade da Informação em que os profissionais dos arquivos e das bibliotecas, os administradores de dados e sistemas de informação e, em geral, os gestores de informação nas organizações desenvolvem a sua actividade (UNIVERSIDADE DO PORTO, 2008).

Portugal conta, atualmente, na área de Ciência da Informação, entre instituições públicas e privadas, com 44 cursos sendo 12 licenciaturas, 11 em nível de especialização, 16 em nível de mestrado e 5 doutoramentos (quadros 5 a 8).

Licenciaturas
\begin{tabular}{|l|l|l|l|}
\hline \multicolumn{2}{|c|}{ Instituiçães Públicas } & \multicolumn{2}{c|}{ Instituiçães Privadas } \\
\hline $\mathbf{1}$ & $\begin{array}{l}\text { Instituto Politécnico de Portalegre, Escola Superior de } \\
\text { Tecnologia e Gestão / Licenciatura em Informação e } \\
\text { Documentação }\end{array}$ & $\mathbf{1}$ & $\begin{array}{l}\text { Universidade Autónoma de Lisboa / } \\
\text { Licenciatura em Ciência da Informação }\end{array}$ \\
\hline $\mathbf{2}$ & $\begin{array}{l}\text { Instituto Politécnico do Porto, Escola Superior de } \\
\text { Estudos Industriais e de Gestão / Bacharelato e } \\
\text { Licenciatura (Licenciatura Bietápica) em Ciências e } \\
\text { Tecnologias da Documentação e Informação }\end{array}$ & $\mathbf{2}$ & $\begin{array}{l}\text { Universidade Católica Portuguesa, } \\
\text { Faculdade de Filosofia de Braga / } \\
\text { Licenciatura em Ciências da Informação e } \\
\text { da Documentação }\end{array}$ \\
\hline $\mathbf{3}$ & $\begin{array}{l}\text { Universidade Aberta / Licenciatura em Ciências da } \\
\text { Informação e da Documentação }\end{array}$ & $\mathbf{3}$ & $\begin{array}{l}\text { Universidade Fernando Pessoa } \\
\text { /Licenciatura em Ciências da Informação } \\
\text { eda Documentação }\end{array}$ \\
\hline $\mathbf{4}$ & $\begin{array}{l}\text { Universidade de Aveiro, Escola Superior de Tecnologia e } \\
\text { Gestão de Águeda / Bacharelato em Documentação e } \\
\text { Arquivística }\end{array}$ & $\mathbf{4}$ & $\begin{array}{l}\text { Universidade Portucalense / Licenciatura } \\
\text { em Ciências da Informação e da } \\
\text { Documentação }\end{array}$ \\
\hline $\mathbf{5}$ & $\begin{array}{l}\text { Universidade de Coimbra, Faculdade de Letras / } \\
\text { Licenciatura em Ciências de Informação, Arquivística e } \\
\text { Biblioteconómica }\end{array}$ & & \\
\hline $\mathbf{6}$ & $\begin{array}{l}\text { Universidade de Évora / Licenciatura em Ciências da } \\
\text { Informação }\end{array}$ & & $\begin{array}{l}\text { Humanas e Sociais / Licenciatura em Ciências } \\
\text { Documentais e Editoriais }\end{array}$ \\
\hline $\mathbf{8}$ & $\begin{array}{l}\text { Universidade do Alarve, Faculdade de Ciências } \\
\text { Universidade do Porto, Faculdade de Letras e Faculdade } \\
\text { de Engenharia / Licenciatura em Ciência da Informação }\end{array}$ & & \\
\hline
\end{tabular}

Quadro 5 - Licenciaturas na área de Ciência da Informação em Portugal.

Fonte: Elaborado pela autora com base em PINTO (2008). 


\section{Especialização}

\begin{tabular}{|l|l|l|l|}
\hline \multicolumn{2}{|c|}{ Instituiçães Públicas } & \multicolumn{2}{c|}{ Instituições Privadas } \\
\hline $\mathbf{1}$ & $\begin{array}{l}\text { Universidade dos Açores, Faculdade de História, } \\
\text { Filosofia e Ciências Sociais / Pós-Graduação em } \\
\text { Ciências Documentais e da Informação }\end{array}$ & $\mathbf{1}$ & $\begin{array}{l}\text { Universidade Portucalense / Especialização } \\
\text { em Ciências da Informação: } \\
\text { Biblioteconomia, Documentação e } \\
\text { Arquivística }\end{array}$ \\
\hline $\mathbf{2}$ & $\begin{array}{l}\text { Universidade da Beira Interior, Departamento de Letras } \\
\text { / Curso de Especialização em Ciências Documentais }\end{array}$ & $\mathbf{2}$ & $\begin{array}{l}\text { Instituto Superior de Línguas e } \\
\text { Administração / Pós-graduação em Ciências } \\
\text { Documentais }\end{array}$ \\
\hline $\mathbf{3}$ & $\begin{array}{l}\text { Universidade de Coimbra, Instituto de Ciências de } \\
\text { Informação Arquivística e Biblioteconómica / } \\
\text { Especialização em Ciências Documentais }\end{array}$ & $\mathbf{3}$ & $\begin{array}{l}\text { Universidade Autónoma de Lisboa / } \\
\text { Especialização em Ciências Documentais }\end{array}$ \\
\hline $\mathbf{4}$ & $\begin{array}{l}\text { Universidade de Lisboa, Faculdade de Direito / } \\
\text { Especialização em Informação e Documentação } \\
\text { Jurídicas }\end{array}$ & $\mathbf{4}$ & $\begin{array}{l}\text { Universidade Fernando Pessoa / Pós- } \\
\text { graduação em Ciências da Informação e da } \\
\text { Documentação }\end{array}$ \\
\hline $\mathbf{5}$ & $\begin{array}{l}\text { Universidade de Lisboa, Faculdade de Letras / } \\
\text { Especialização em Ciências Documentais }\end{array}$ & $\begin{array}{l}\text { Universidade Lusófona de Humanidades e } \\
\text { Tecnologias Lisboa / Especialização em } \\
\text { Ciências Documentais }\end{array}$ \\
\hline $\mathbf{6}$ & $\begin{array}{l}\text { Universidade Nova de Lisboa, Faculdade de Ciências } \\
\text { Sociais e Humanas / Especialização em Ciências da } \\
\text { Informação e da Documentação }\end{array}$ & & \\
\hline
\end{tabular}

Quadro 6 - Especializações na área de Ciência da Informação em Portugal.

Fonte: Elaborado pela autora com base em PINTO (2008).

\section{Mestrado}

\begin{tabular}{|c|c|c|c|}
\hline \multicolumn{2}{|r|}{ Instituições Públicas } & \multicolumn{2}{|r|}{ Instituições Privadas } \\
\hline 1 & $\begin{array}{l}\text { Universidade Aberta / Mestrado em Gestão } \\
\text { da Informação e Bibliotecas Escolares }\end{array}$ & 1 & $\begin{array}{l}\text { Universidade Autónoma de Lisboa / Mestrado em } \\
\text { Ciências Documentais }\end{array}$ \\
\hline 2 & $\begin{array}{l}\text { Universidade de Aveiro, Departamento de } \\
\text { Economia Gestão e Engenharia Industrial / } \\
\text { Mestrado em Gestão de Informação }\end{array}$ & 2 & $\begin{array}{l}\text { Universidade Católica Portuguesa, Faculdade de } \\
\text { Filosofia / Mestrado em Ciências da Informação e da } \\
\text { Documentação }\end{array}$ \\
\hline 3 & $\begin{array}{l}\text { Universidade do Algarve, Faculdade de } \\
\text { Ciências Humanas e Sociais / Mestrado em } \\
\text { Ciências Documentais }\end{array}$ & 3 & $\begin{array}{l}\text { Universidade Lusófona de Humanidades e } \\
\text { Tecnologias / Mestrado em Ciências Documentais }\end{array}$ \\
\hline 4 & $\begin{array}{l}\text { Universidade de Évora, Departamento de } \\
\text { História / Mestrado em Ciências Documentais }\end{array}$ & 4 & $\begin{array}{l}\text { Universidade Lusófona de Humanidades e } \\
\text { Tecnologias / Mestrado em Bibliotecas Escolares e } \\
\text { Literacias do Séc. XXI }\end{array}$ \\
\hline 5 & $\begin{array}{l}\text { Universidade de Lisboa, Faculdade de } \\
\text { Psicologia / Mestrado em Educação e Leitura }\end{array}$ & 5 & $\begin{array}{l}\text { Universidade Lusófona de Humanidades e } \\
\text { Tecnologias Lisboa / Mestrado em Gestão do } \\
\text { Conhecimento e da Informação em Contexto Digital }\end{array}$ \\
\hline 6 & $\begin{array}{l}\text { Universidade do Minho / Mestrado em } \\
\text { Ciência da Informação }\end{array}$ & 6 & $\begin{array}{l}\text { Universidade Fernando Pessoa, Faculdade de } \\
\text { Ciências Humanas e Sociais / Mestrado em Ciências } \\
\text { da Informação e da Documentação }\end{array}$ \\
\hline 7 & $\begin{array}{l}\text { Universidade do Porto, Faculdade de } \\
\text { Engenharia e Faculdade de Letras / Mestrado } \\
\text { em Ciência da Informação }\end{array}$ & 7 & $\begin{array}{l}\text { Universidade Portucalense / Mestrado em Educação e } \\
\text { Bibliotecas }\end{array}$ \\
\hline 8 & $\begin{array}{l}\text { Universidade Nova de Lisboa, Faculdade de } \\
\text { Ciências Sociais e Humanas / Ciências da } \\
\text { Informação e da Documentação }\end{array}$ & & \\
\hline 9 & $\begin{array}{l}\text { Universidade de Coimbra, Faculdade de } \\
\text { Letras /Mestrado em Informação, } \\
\text { Comunicação e Novos Media. }\end{array}$ & & \\
\hline
\end{tabular}

Quadro 7- Mestrados na área de Ciência da Informação em Portugal.

Fonte: Elaborado pela autora, com base em PINTO (2008). 


\section{Doutoramento}

\begin{tabular}{|c|l|c|l|}
\hline \multicolumn{1}{|c|}{ Instituições Públicas } & \multicolumn{1}{c|}{ Instituições Privadas } \\
\hline $\mathbf{1}$ & $\begin{array}{l}\text { Universidade de Aveiro/ Universidade do } \\
\text { Porto, Faculdade de Letras -Doutoramento } \\
\text { em Informação e Comunicação em } \\
\text { Plataformas Digitais }\end{array}$ & $\mathbf{1}$ & $\begin{array}{l}\text { Universidade Fernando Pessoa - Doutoramento em } \\
\text { Ciências da Informação }\end{array}$ \\
\hline $\mathbf{2}$ & $\begin{array}{l}\text { Universidade do Porto, Faculdade de Letras - } \\
\text { Doutoramento em Ciência da Informação }\end{array}$ & $\mathbf{2}$ & $\begin{array}{l}\text { Universidade Lusófona de Humanidades e } \\
\text { Tecnologias em convénio com a Universidad de Alcalá } \\
\text { - Doutoramento em "Documentación e Información" }\end{array}$ \\
\hline $\mathbf{3}$ & $\begin{array}{l}\text { Universidade de Coimbra, Instituto de } \\
\text { Ciências de Informação Arquivística e } \\
\text { Biblioteconómica - Doutoramento na Área de } \\
\text { Ciência da Informação Arquivística e } \\
\text { Biblioteconómica }\end{array}$ & & \\
\hline
\end{tabular}

Quadro 8 - Doutoramentos na área de Ciência da Informação em Portugal.

Fonte: Elaborado pela autora com base em PINTO (2008).

\section{CONSIDERAÇÕES FINAIS}

Mostrar a evolução da Ciência da Informação no Brasil e em Portugal, bem como possíveis semelhanças e/ou diferenças ou pontos em comum foi o propósito deste artigo. O que se evidencia como uma grande diferença entre os dois países é a concepção das formações que evoluíram para a $\mathrm{Cl}$ ou seja a de bibliotecários, documentalistas e arquivistas. Em Portugal elas nasceram conjuntamente por meio do Curso de bibliothecarioarchivista evoluindo para as licenciaturas, e as pós-graduações onde verifica-se a existência de um núcleo comum de interesse, que permite uma convergência de conteúdos básicos para a formação profissional com a identificação de pontos comuns permitindo o diálogo e aproximação das profissões.

No Brasil os cursos iniciais destinados a formação desses profissionais nasceram e permanecem, até hoje, sendo ofertados separadamente. Atualmente o Brasil conta com 43 escolas que oferecem cursos de graduação na área, 12 mestrados e 6 doutorados.

Em Portugal a Ciência da Informação tem recebido contribuições de áreas como as chamadas ciências documentais, mais diretamente relacionadas com a arquivologia e a biblioteconomia, a comunicação social, os sistemas de informação de gestão ou as tecnologias da informação. Ciência ainda jovem e em formação, em Portugal a Ciência da Informação tem procurado, por meio das licenciaturas e de estruturas que promovam o seu desenvolvimento, a sua disseminação e a sua afirmação nomeadamente em nível de mestrado e doutorado, pois é por meio da investigação, que se atinge a prossecução

\footnotetext{
${ }^{4}$ Neste doutoramento o grau é atribuído conjuntamente pela Universidade de Aveiro e pela Universidade do Porto.
} 
desses objetivos. Prova disso é que atualmente, Portugal conta com 12 licenciaturas, 16 mestrados e 5 doutoramentos na área de $\mathrm{Cl}$. demonstrando, desta forma, a preocupação dos profissionais envolvidos.

\section{REFERÊNCIAS}

BARBOSA, R.R. et al. Novo nome e novo paradigma: da biblioteconoma à ciência da informação. Perspectivas em Ciência da Informação, Belo Horizonte, v.5, n. especial, p.81-91, jan./jun. 2000.

CARDOSO, A.M.P. Educação para a informação: desafios contemporâneos para a ciência da informação. DataGramaZero- Revista de Ciência da Informação, v.3, n.5 out. 2002. Disponível em:<http://www.dgz.org.br/out02/Art_06.htm>. Acesso em: 5 set. 2007.

GOMES, H. E.; ZAHER, C. R. A experiência do IBBD na preparação de cientistas da informação. In: SEMINÁRIO LATINO-AMERICANO SOBRE PREPARAÇÃO DE CIENTISTAS DA INFORMAÇÃO, 1., México, 1972. Anais... Rio de Janeiro: Instituto Brasileiro de Bibliografia e Documentação, 1972. p. 315-323.

NAGLE, J.; CASALECCHI , J. Ê. Projeto acadêmico-pedagógico. São Paulo: Fundação Escola de Sociologia e Política de São Paulo. Disponível em: $<$ http://www.fespsp.org.br/04-ProjetoAcademicoPedagogico.pdf>. Acesso em: 11 out. 2007.

ODDONE, N. Lydia de Queiroz Sambaquy e a Ciência da Informação no Brasil. In: ENCONTRO NACIONAL DE PESQUISA EM CIÊNCIA DA INFORMAÇÃO (ENANCIB), 6. 2005. Anais eletrônicos... Florianópolis, SC. Disponíverl em: <http://www.arquivar.com.br/espaco_profissional/sala_leitura/teses-dissertacoes-emonografias/Lydia_e_a_Ciencia_da_Informacao_no_Brasil.pdf>. Acesso em. 26 Jun.2007.

O IBBD e a informação científica: uma perspectiva histórica para a ciência da informação no Brasil. Ciência da Informação, Brasília, v. 35, n. 1, p. 45-56, jan./abr. 2006.

PENTEADO, P. Das "ciências" documentais à ciência da informação: ensaio epistemológico para um novo modelo curricular: Recensão. Arquivística.net (www.arquivistica.net), Rio de Janeiro, v.1, n.2, p. 95-103, jul./dez. 2005.

PINHEIRO, L.V.R.; LOUREIRO, J.M.M. Traçados e limites da ciência da informação. Ciência da Informação, Brasília, v. 24, n.1, p. 42-53, 1995.

PINTO, M. M. G. A. A formação em informação e documentação: Portugal na contemporaneidade. In: ENCUENTRO IBÉRICO DE DOCENTES E INVESTIGADORES EN INFORMACIÓN Y DOCUMENTACIÓN, 3., Salamanca 5 a 7 de Maio de 2008. Anais... Salamanca, Universidade de Salamanca, 2008, p. 91-144.

RIBEIRO, F. O desafio da formação profissional: novo paradigma, novo modelo formativo. CONGRESSO INTERNACIONAL DE ARQUIVOS, CENTROS DE DOCUMENTAÇÃO E MUSEUS, 1. Anais... São Paulo: INTEGRAR, 2002. p. 418-440. 
RIBEIRO, F. O ensino da paleografia e da diplomática no curso de BibliotecárioArquivista. In: Estudos em homenagem ao Professor Doutor José Marques. Org. Departamento de Ciências e Técnicas do Património, Departamento de História. Porto: Faculdade de Letras da Universidade do Porto, 2006a. Disponível em: $<$ http://repositorio.up.pt/aberto/bitstream/10216/7741/2/4847.pdf>. Acesso em: 21 out. 2006.

RIBEIRO, F.; LEITE, J.; CERVEIRA, M. E. Memória do Curso de Especialização em Ciências Documentais (1985-2003). In: Homenagem ao Professor Doutor José Marques: 26 e 27 de Junho de 2003. Org. [da] Secção de Ciências Documentais, Departamento de Ciências e Técnicas do Património, Faculdade de Letras da Universidade do Porto. Porto : FLUP, 2004. Disponível em: <http://ler.letras.up.pt/uploads/ficheiros/artigo5651.PDF>. Acesso em: 16 maio 2007.

SILVA, A.B.M.; RIBEIRO, F. Das ciências documentais à ciência da informação: ensaio epistemológico para um novo modelo curricular. Porto: Afrontamento, 2002.

UNIVERSIDADE DO PORTO. Licenciatura em Ciência da Informação. Disponível em: <http://sigarra.up.pt/flup/cursos_geral.FormView?P_CUR_SIGLA=LCINF>Acesso em: 07 jan. 2008.

VALENTIM, M. L. P. Construção de conhecimento científico. In: (Org.). Métodos qualitativos de pesquisa em Ciência da Informação. São Paulo: Polis, 2005. p.7-28.

\title{
Title
}

Courses on Information Science in Brazil and in Portugal: diachronic perspectives

\begin{abstract}
It presents a historic retrospective of Information Science in Brazil and in Portugal. The Information Science was introduced in Brazil in the 70's with the implementation of a masters degree in the Brazilian Institute of Bibliography and Documentation (IBBD) and in Portugal it emerged from the post-graduation courses in Documentation Science that evolved towards the adoption of the term Information Science, with its implementation in 2001, a joint effort between the Faculty of Engineering and Faculty of Arts of the first graduate course in $\mathrm{Cl}$. In this sense it shows the differences and similarities as well as the actual state of $\mathrm{Cl}$ in both countries.
\end{abstract}

\section{Key words}

Information Science - Brazil; Information Science - Portugal. 


\section{Titulo}

Cursos de ciencia de la informacion en Brasil y en Portugal: perspectivas diacrónicas

\section{Resumen}

Presenta una retrospectiva histórica de la Ciencia de la Información (Cl) en Brasil y Portugal. La Ciencia de la Información se introdujo en Brasil los años 70 con la creación de un curso de mestrado en el Instituto Brasileño de Bibliografía y Documentación (IBBD) y en Portugal, surgió de los cursos de post-grado en Ciencias Documentales, que han evolucionado hacia la adopción del término Ciencia de la información, con miras a la aplicación en 2001, en un esfuerzo conjunto entre la Facultad de Ingeniería y la Facultad de Letras de la primer licenciatura en CI. En este sentido, destaca las diferencias y similitudes, así como la imagen actual de la Cl en ambos países.

\section{Palabras clave}

Ciencia de la Información, Brasil; Ciencias de la Información, Portugal.

Recebido em:

Aceito em: 